\title{
Psychiatric co-morbidity among male heroin addicts: differences between hospital and incarcerated subjects in Taiwan
}

\section{CHIAO-CHICY CHEN, ${ }^{1,2,3}$ SHANG-YING TSAI, ${ }^{2}$ LIEN-WEN SU, ${ }^{1}$ TIEN-WEI YANG, ${ }^{1}$ CHANG-JER TSAI ${ }^{1} \&$ HAI-GWO HWU ${ }^{3}$}

${ }^{1}$ Department of Adult Psychiatry, Taipei City Psychiatric Center, ${ }^{2}$ Department of Psychiatry, Taipei Medical College $\mathcal{E}{ }^{3}$ Department of Psychiatry, College of Medicine, National Taiwan University, Taipei, Taiwan

\begin{abstract}
Aims. To examine the differences in psychiatric co-morbidity between hospital and incarcerated groups of heroin addicts in Taiwan. Design. Life-time prevalence of DSM-III-R-based coexisting psychiatric disorders, including personality disorders, were surveyed. Settings. A psychiatric hospital and two prisons. Participants. Two hundred and sixty heroin users who were incarcerated in prisons, and 47 heroin users who voluntarily sought help in a psychiatric hospital were interviewed by board-certified psychiatrists. Measurements. Using two psychometric instruments, the Psychiatric Diagnostic Assessment (PDA) and the Structured Interview for DSM-III-R Personality Disorders (SIPD-R), psychiatric co-morbidity was assessed. Findings. Different life-time rates of coexisting psychiatric disorders among heroin addicts in different settings were found: $83 \%$ of hospital subjects and $66 \%$ of incarcerated subjects were diagnosed as having at least one coexisting axis I or II disorder. The most prevalent coexisting DSM-III-R defined axis I disorders were additional substance use disorders (alcohol and methamphetamine), while the axis II disorder was antisocial personality disorder. The hospital group had a significantly higher prevalence rate of mood disorder $(p<0.001)$, paranoid personality disorder $(p<0.05)$ and antisocial personality disorder $(p<0.001)$ than the incarcerated group. Conclusions. We suggest that heroin addicts with coexisting psychiatric disorders receive relevant psychiatric treatment. Those with personality disorders, especially the antisocial type, should be considered for specialized therapeutic community programmes instead of incarceration.
\end{abstract}

\section{Introduction}

An association between drug addiction and psychopathology has been frequently mentioned in the literature. Drug addicts have been shown to have high rates of depression, ${ }^{1-3}$ personality dis- orders $^{4-6}$ and minor psychopathology. ${ }^{7,8}$ Coexisting psychiatric illness can interfere with the course and treatment of drug dependence. Kosten et al. reported, in a 2.5-year follow-up study, that opioid users diagnosed as depressed

Correspondence to: Chiao-Chicy Chen MD, PhD, Department of Adult Psychiatry, Taipei City Psychiatric Center, 309 Sung-Te Road, Taipei, 1 10, Taiwan. Tel: + 8862 27263141, ext. 1347; fax: + 886227596383 ; e-mail: CChen@mail.tcpc.gov.tw

Submitted 27 th February 1998; initial review completed 3rd July 1998; final version accepted 1st December 1998. 
at the beginning of treatment were less likely to be abstinent at follow-up than other opioid users with a normal affect. ${ }^{9}$ Rounsaville et al. also found that success and failure in opioid detoxification were best predicted by initial psychiatric symptomatology. ${ }^{10}$ In a study of co-morbid personality disorder among drug addicts, Khantzian \& Treece concluded that substance use disorders and personality disorders are inextricably intertwined, each affecting the other. ${ }^{11}$

As in many countries, drug abuse has become a problem in Taiwan. Since 1989 there has been a dramatic increase in methamphetamine and heroin abuse. According to the statistics of the National Department of Justice, approximately 20000 people are currently incarcerated in jails for drug abuse (mainly methamphetamine and heroin). Societies that indiscriminately quarantine drug addicts to prevent spread to the general population have been criticized. ${ }^{12}$ Unfortunately, this remains the main strategy in dealing with drug addicts in Taiwan. According to the Narcotic Exclusion Act, which was enacted in 1955, drug abuse and dependence are viewed as criminal behaviours. Repeat offenders (namely chronic users) may be punished with a life sentence. Recently, this issue has raised several concerns. For example, it was argued that the law deprives heroin addicts of the right to access to treatment in the presence of coexisting psychiatric disorders.

Most of the studies concerning the psychiatric co-morbidity of heroin addiction were carried out in clinical settings or voluntarily. ${ }^{1-8}$ Because of drug policy in Taiwan, a large number of heroin addicts are incarcerated in prisons. We suspected that the incarcerated heroin addicts also suffer from a high prevalence of coexisting psychopathological conditions. To clarify this issue, the present study was designed to examine the life-time prevalence of coexisting DSM-IIIR-based psychiatric disorders, including personality disorders, among male heroin addicts who sought treatment voluntarily in a psychiatric hospital (hospital group) and among former addicts who were in prison (incarcerated group). The result may provide information for the strategy of tertiary prevention of heroin addiction.

\section{Method}

Subjects

The subjects were exclusively male, because over
$80 \%$ of the heroin addicts in Taiwan are male. All the subjects were interviewed by a boardcertified psychiatrist. Only the subjects who met the diagnostic criteria of opioid dependence by DSM-III-R were recruited. There were three groups of subjects in this study. The first group consisted of 47 heroin addicts who sought treatment voluntarily at Taipei City Psychiatric Center between October 1994 and May 1995. They were recruited consecutively after giving written informed consent. Their mean age was $35.2 \pm 10.2$ years with a mean duration of heroin use of $5.1 \pm 8.6$ years. The second group consisted of 134 incarcerated heroin addicts who were randomly selected in Yunlin prison. This prison, located in central Taiwan, is where firsttime offenders of heroin dependence are incarcerated. The subjects had a mean age of $33.7 \pm 7.9$ years with a mean duration of heroin use of $3.1 \pm 5.0$ years. The third group was composed of 126 incarcerated heroin addicts randomly selected in Penghu prison. This prison, located on an offshore island near the west coast of Taiwan, houses the repeat offenders of the Narcotic Exclusion Act. The subjects had a mean age of $36.6 \pm 8.8$ years with a mean duration of heroin use of $6.3 \pm 7.1$ years. The incarcerated group was studied from September 1995 to May 1996.

\section{Procedure}

The hospital subjects $(n=47)$ were interviewed on either an inpatient $(n=41)$ or outpatient $(n=6)$ basis. For inpatients, the interview was carried out on the ward at least 14 days after standard detoxification treatment with daily oral clonidine, $8-17 \mathrm{mcg} / \mathrm{kg}$ body weight for 7 days. The outpatient interview was made by appointment via a research assistant and all interviewees were heroin-free for at least 14 days before the interview was conducted. For the incarcerated subjects, the interviews were conducted in the prisons. In each prison, there were 2000 people who were sentenced because of illegal use of heroin. We first obtained permission from the National Department of Justice to contact the individual prison authorities. Then we randomly and anonymously selected $7.5 \%$ of prisoners $(n=150)$ according to their prison number sequence based on a random table. Forty cases were excluded after initial interview because they did not meet the diagnostic criteria of opioid 
dependence of DSM-III-R. In all, 134 men in Yunlin prison and 126 men in Penghu prison completed the interview. All subjects were assured that all information provided was strictly confidential. Informed consent was obtained before the interview started. Each subject (either hospital or prison) was interviewed privately. Each interview generally took 60-90 minutes.

\section{Psychiatric interview}

All the subjects were interviewed by five boardcertified psychiatrists (CCC, SYT, LWS, TWY and CJT) using two psychometric instruments, the Psychiatrist's Diagnostic Assessment $(\mathrm{PDA})^{13}$ and the Structured Interview for DSMIII-R Personality Disorders (SIPD-R). ${ }^{14}$ The PDA was originally designed based on the Diagnostic and Statistical Manual (DSM-III, APA) for Chinese-speaking psychiatrists to make a current and/or life-time diagnosis in clinical practice and research. The PDA has also proved to have satisfactory validity over the psychiatric disorders according to DSM-III-R criteria. ${ }^{15}$ The five interviewers for this study had similar training and were familiar with PDA. The inter-rater reliability estimates for life-time occurrence of various psychiatric disorders ranged from 0.93 to 1.00, indicating a high level of agreement for specific diagnostic categories. ${ }^{15}$ The SIPD-R is a revision of the SIPD. The SIPD is a semi-structured interview which was developed to improve axis II diagnostic reliability of DSM-III. The overall organization of the SIPD-R is similar to the SIPD, which includes 17 topical sections. Within each section is a set of questions followed by the DSM-III-R personality criteria to be rated from those questions. Level 0 corresponds to not present; levels 1 and 2 correspond to moderately and severely present. According to the rating instructions, level 1 is interpreted as sufficient to rate criteria as present. The SIPD has been used in numerous studies and translated into six languages, which has been found to be reliable. ${ }^{16-18}$. A copy of the SIPD-R was generously provided by Dr Bruce Pfohl at Department of Psychiatry of the University of Iowa, USA, where the instrument was developed. The SIPD-R was translated into Chinese by the authors, and then translated back to English by a clinical psychologist and discussed by the authors. The reliability of SIPD-R was studied by two psychiatrists (CCC and SYT) who simultaneously interviewed 20 hospital cases of heroin dependence. The overall agreement for the presence or absence of a personality disorder was 18/20 $(90 \%)$, which yields a kappa value of 0.79 . The other three interviewers were trained to use SIPD-R prior to the study.

\section{Results}

Demographic characteristics and heroin use history

Table 1 shows the socio-demographic characteristics and heroin use history of the three studied groups, namely hospital (TCPC), Yunlin prison and Penghu prison. Significant differences among the three groups were found in education $\left(\chi^{2}=15.91, \quad p=0.0004\right)$ and social class (Hollingshead's classification) $\quad\left(\chi^{2}=15.86\right.$, $p<0.001)$. The voluntary subjects in TCPC tended to have been better educated ( $>9$ years) and to have a higher socio-economic status (Hollingshead's classification IV or V) compared to incarcerated subjects. There were no significant differences among the three groups in age or marital status, but the cases in Yunlin prison (first offenders) were younger (more cases below 35 years old). Although the age for firsttime heroin use was not different among the three groups, there were more repeat offenders whose duration of heroin use was longer than 8 years $\left(\chi^{2}=33.44, p<0.001\right)$.

\section{Life-time prevalence of coexisting DSM-III-R diag- nosis}

Table 2 shows the life-time prevalence of axis I and axis II disorders. In addition to heroin dependence, the most prevalent coexisting axis I psychiatric disorder was substance use disorders, i.e. methamphetamine dependence (38.3\%, $34.3 \%$ and $30.2 \%$, respectively) and alcohol dependence $(19.1 \%, 12.7 \%$, and $8.7 \%$, respectively). Dysthymia $(14.9 \%, 3.0 \%$, and $4.8 \%)$ and major depression $(8.5 \%, 2.2 \%$, and $3.0 \%)$ were prominent, as was generalized anxiety disorder $(6.4 \%, 5.2 \%$, and $3.7 \%$ ) (see Table 2). It is interesting to find that the life-time prevalence of mood disorders was significantly higher in the TCPC group than the other two incarcerated groups $\left(\chi^{2}=13.57, p=0.001\right)$. According to DSM-III-R diagnostic criteria, $61.7 \%$ of TCPC subjects, $51.5 \%$ of Yunlin subjects and $42.9 \%$ of Penghu subjects, respectively, met diagnostic criteria for at least one axis I disorder. Further- 
Table 1. Socio-demographic characteristics and heroin use history

\begin{tabular}{|c|c|c|c|}
\hline & \multirow{2}{*}{$\begin{array}{c}\text { Hospital subjects } \\
\text { TCPC }\end{array}$} & \multicolumn{2}{|c|}{ Incarcerated subjects } \\
\hline & & Yunlin prison & Penghu prison \\
\hline Age (years) $(\%)$ & $N=47$ & $N=134$ & $N=126$ \\
\hline 35 & $23(48.9)$ & $85(63.4)$ & $64(50.8)$ \\
\hline 35 & $24(51.1)$ & $49(36.6)$ & $62(49.2)$ \\
\hline Education (years) $(\%)^{\star}$ & $N=47$ & $N=134$ & $N=126$ \\
\hline 9 & $18(38.3)$ & $75(56.0)$ & 89 (70.6) \\
\hline 9 & $29(61.7)$ & $59(44.0)$ & $37(29.4)$ \\
\hline Social class $(\%)^{\star}$ & $N=42$ & $N=106$ & $N=111$ \\
\hline I-III & $9(21.4)$ & $7(6.6)$ & $3(2.7)$ \\
\hline IV-V & $33(78.6)$ & $99(93.4)$ & $108(97.3)$ \\
\hline Marital status (\%) & $N=45$ & $N=134$ & $N=126$ \\
\hline Single & $19(42.2)$ & $70(52.2)$ & $66(52.4)$ \\
\hline Married & $20(44.4)$ & $44(32.8)$ & $32(25.4)$ \\
\hline Divorced & $6(13.3)$ & $20(14.9)$ & $28(22.2)$ \\
\hline Age first heroin use (years) $(\%)$ & $N=44$ & $N=127$ & $N=117$ \\
\hline 25 & $18(40.9)$ & $43(33.9)$ & $47(40.2)$ \\
\hline 25 & $26(59.1)$ & $84(66.1)$ & $70(59.8)$ \\
\hline Years since heroin use began $(\%)^{\star}$ & $N=45$ & $N=126$ & $N=117$ \\
\hline 2 & $14(31.1)$ & $63(50.0)$ & $42(35.9)$ \\
\hline $2-8$ & $26(57.8)$ & $53(42.1)$ & $40(34.2)$ \\
\hline 8 & $5(11.1)$ & $10(7.9)$ & $35(29.9)$ \\
\hline
\end{tabular}

${ }^{\star} p<0.001$ compared between hospital subjects and incarcerated subjects.

more, according to SIPD-R $66.0 \%, 36.6 \%$ and $42.1 \%$ of individual group, respectively, met at least one axis II disorder of the DSM-III-R diagnostic criteria. The most common diagnosis was antisocial personality disorder, followed by paranoid personality disorder, obsessive-compulsive personality disorder and histrionic personality disorder. The life-time prevalence of paranoid personality disorder $\left(\chi^{2}=8.81, p<0.05\right)$ and antisocial personality disorder $\left(\chi^{2}=21.93\right.$, $p<0.001$ ) were significantly higher in the TCPC subjects than the other two subjects. Overall, $83.0 \%, 67.9 \%$ and $63.5 \%$ of cases in each group met the diagnostic criteria for at least one axis I or axis II disorder.

Correlates of personality disorders with psychosocial characteristics

Table 3 shows the demographic and psychosocial correlates of personality disorders. No significant associations were found between the groups for age, educational level, marital status, years since heroin use began (namely history of heroin use), criminal record other than heroin addiction and frequency of co-morbid physical illness. Significant differences were found in several areas: (1) social class: those heroin addicts with personality disorders were more frequently distributed in middle-upper (I-III) class than those without personality disorders $(p<0.05)$; (2) age of first heroin use: subjects with personality disorders were more likely to initiate their heroin use before 25 years of age, while the subjects without any personality disorder usually began to use heroin after 25 years of age $(p<0.01)$; (3) co-morbid with axis I disorders: individuals with a personality disorder were more likely than those without a personality disorder to have a coexisting axis-I disorder $(p<0.001)$.

\section{Discussion}

Because of drug policy in Taiwan, most heroin addicts are unlikely to receive a psychiatric interview unless they become incarcerated. The majority of heroin addicts in the community never reveal their condition, and only a small proportion of addicts voluntarily seeks psychiatric help. Thus, the subjects of the present study are 
Table 2. Life-time prevalence of DSM-III-R based psychiatric disorders among male heroin addicts

\begin{tabular}{|c|c|c|c|}
\hline \multirow[b]{2}{*}{ DSM-III-R diagnosis } & \multirow{2}{*}{$\begin{array}{c}\text { Hospital subjects } \\
\text { TCPC } \\
N=47(\%)\end{array}$} & \multicolumn{2}{|c|}{ Incarcerated subjects } \\
\hline & & $\begin{array}{l}\text { Yunlin prison } \\
N=134(\%)\end{array}$ & $\begin{array}{c}\text { Penghu prison } \\
N=126(\%)\end{array}$ \\
\hline \multicolumn{4}{|l|}{ Axis I disorders } \\
\hline \multicolumn{4}{|l|}{ Mood disorders } \\
\hline Major depression $\star$ & $4(8.5)$ & $3(2.2)$ & $4(3.0)$ \\
\hline Dysthymia & $7(14.9)$ & $4(3.0)$ & $6(4.8)$ \\
\hline Cyclothymia & $0(0.0)$ & $0(0.0)$ & $1(0.8)$ \\
\hline \multicolumn{4}{|l|}{ Somatoform disorders } \\
\hline Somatization disorder & $1(2.1)$ & $2(1.5)$ & $0(0.0)$ \\
\hline Hypochondriacal disorder & $1(2.1)$ & $1(0.7)$ & $0(0.0)$ \\
\hline Conversion disorder & $1(2.1)$ & $0(0.0)$ & $0(0.0)$ \\
\hline \multicolumn{4}{|l|}{ Psychological factors affecting } \\
\hline \multicolumn{4}{|l|}{ Anxiety disorders } \\
\hline Generalized anxiety disorder & $3(6.4)$ & $7(5.2)$ & $5(3.7)$ \\
\hline Panic disorder & $0(0.0)$ & $1(0.7)$ & $0(0.0)$ \\
\hline Obsessive-compulsive disorder & $1(2.1)$ & $0(0.0)$ & $1(0.8)$ \\
\hline Schizophrenic disorders & $0(0.0)$ & $0(0.0)$ & $1(0.8)$ \\
\hline Alcoholism dependence & $9(19.1)$ & $17(12.7)$ & $11(8.7)$ \\
\hline Methamphetamine dependence & $18(38.3)$ & $46(34.3)$ & $38(30.2)$ \\
\hline At least one Axis I disorder & $29(61.7)$ & $69(51.5)$ & $54(42.9)$ \\
\hline \multicolumn{4}{|l|}{ Axis II disorders } \\
\hline Paranoid $†$ & $5(10.6)$ & $6(4.5)$ & $1(0.8)$ \\
\hline Antisocial* & $29(61.7)$ & $39(29.1)$ & $51(40.5)$ \\
\hline Others $\ddagger$ & $9(19.1)$ & $20(14.9)$ & $15(11.9)$ \\
\hline At least one Axis II disorder & $31(66.0)$ & $49(36.6)$ & $53(42.1)$ \\
\hline At least one Axis I or II disorder & $39(83.0)$ & $91(67.9)$ & $80(63.5)$ \\
\hline
\end{tabular}

$\star p<0.001 ; \dagger p<0.05$ compared between hospital subjects and incarcerated subjects.

‡ Including: schizoid, schizotypal, histrionic, narcissistic, borderline, obsessive-compulsive, dependent, avoidance, passive-aggressive, self-defeating personality disorders.

not representative of the Taiwanese population of heroin addicts as a whole. Nevertheless, the results of the present study are consistent with previous studies that found a high prevalence of various psychiatric disorders among narcotic addicts. ${ }^{1-8}$ In this study, $83 \%$ of hospital subjects and $66 \%$ of incarcerated subjects of heroin addiction were diagnosed with either at least one axis I disorder (including alcohol dependence and methaphetamine dependence) or one axis II disorder (see Table 2). The most prevalent coexisting axis I disorders were additional substance use disorders, followed by mood disorders and anxiety disorders. Major psychosis, such as schizophrenia, was rarely seen (only one case). Antisocial personality disorder was the most significant axis II diagnosis. The overall life-time rate of coexisting psychiatric disorders found in this study was significantly higher than those reported in community populations in Taiwan; ${ }^{1,9}$ in particular, the rate of alcohol dependence, affective disorder and antisocial personality disorder. According to $\mathrm{Hwu}$ et al., life-time rate (aged 18-64 years) was 1.5\% for alcohol dependence, $1.5 \%$ for major depression, and was $0.1 \%$ for antisocial personality disorder. This result strongly suggests the importance of psychopathological assessment of heroin addicts in any settings.

In this study, there was a high rate of additional substance use disorders (co-dependence) among heroin addicts, including alcohol dependence and, in particular, methamphetamine dependence (see Table 2). Ross et al. have suggested that the prevalence of one drug-related diagnosis increased significantly the odds of having almost any other drug-related diagnosis. ${ }^{3}$ Alcohol use is a common problem among heroin addicts, and was estimated to range from $30 \%$ to $35 \%$ according to various studies. ${ }^{20-22}$ The much 
Table 3. Comparison of psychosocial variables between male heroin addicts with and without personality disorders

\begin{tabular}{|c|c|c|}
\hline Variables $(\%)$ & $\begin{array}{c}\text { With personality disorders } \\
N=133(\%)\end{array}$ & $\begin{array}{l}\text { Without personality disorders } \\
\qquad N=174(\%)\end{array}$ \\
\hline \multicolumn{3}{|l|}{ Age (years) } \\
\hline$\leq 35$ & $76(57.1)$ & $96(55.2)$ \\
\hline$>35$ & $57(42.9)$ & $78(44.8)$ \\
\hline \multicolumn{3}{|c|}{ Education (years) } \\
\hline$\leq 9$ & $74(55.6)$ & $108(62.1)$ \\
\hline$>9$ & $59(44.4)$ & $66(37.9)$ \\
\hline \multicolumn{3}{|l|}{ Social class $\star$} \\
\hline I-III & $12(11.1)$ & $7(4.6)$ \\
\hline IV-V & $96(88.9)$ & $144(95.4)$ \\
\hline \multicolumn{3}{|l|}{ Marital status } \\
\hline Single & $74(55.6)$ & $81(47.1)$ \\
\hline Married & $33(24.8)$ & $63(36.6)$ \\
\hline Divorced & $26(19.6)$ & $28(16.3)$ \\
\hline \multicolumn{3}{|c|}{ Age first heroin use (years) $\dagger$} \\
\hline$\leq 25$ & $58(47.2)$ & $50(30.3)$ \\
\hline$>25$ & $65(52.9)$ & $115(69.7)$ \\
\hline \multicolumn{3}{|c|}{ Years since heroin use began } \\
\hline$\leq 1$ & $28(22.6)$ & $50(30.5)$ \\
\hline$>1$ & $96(77.4)$ & $114(69.5)$ \\
\hline \multicolumn{3}{|c|}{$\begin{array}{l}\text { Additional criminal record other } \\
\text { than heroin addiction }\end{array}$} \\
\hline Yes & $37(27.8)$ & $37(21.3)$ \\
\hline No & $96(72.2)$ & $137(78.7)$ \\
\hline \multicolumn{3}{|c|}{ Co-morbid with Axis I disorders $\ddagger$} \\
\hline Yes & $33(24.8)$ & $12(6.9)$ \\
\hline No & $100(75.2)$ & $162(93.1)$ \\
\hline \multicolumn{3}{|c|}{ Co-morbid with physical illness } \\
\hline Yes & $34(25.6)$ & $39(22.4)$ \\
\hline No & $99(74.4)$ & $135(77.6)$ \\
\hline
\end{tabular}

lower co-morbid rate of alcohol dependence in our study (8.7-19.1\%) may have been due to the protective effect of a deficiency of genetically determined alcohol-metabolizing enzymes in the population. ${ }^{23}$ The rate of co-morbid methamphetamine dependence was relatively high (30$38 \%$ ) in this study. There are few similar reports on co-dependence of methamphetamine dependence among heroin addicts. One study showed $24-25 \%$ of stimulant dependence among opioid addicts. $^{24}$

In this study, subjects with additional substance use disorders, i.e. coexisting alcohol and/ or methamphetamine dependence, had a higher rate of co-morbid axis I disorders in hospital subjects than incarcerated subjects $\left(\chi^{2}=14.01\right.$, $p<0.001)$. Population samples are known to affect co-morbidity rates when studying co-morbid disorders. ${ }^{25}$ This effect is stated clearly in Berkson's fallacy: because people with two or more disorders are more likely to enter treatment than those with one disorder, co-morbidity rates tend to be higher in samples of patients in treatment settings. ${ }^{26}$ Moreover, different patient populations do not necessarily have equivalent co-morbidity rates. The results of the present study also revealed a similar trend, i.e. that psychiatric co-morbidity is higher in hospital than in incarcerated populations.

Although the study group was small, hospital subjects in this study had a significantly higher life-time rate of DSM-III-R-based mood disorders (dysthymia and major depression) and axis II disorders compared to incarcerated subjects, particularly antisocial personality disorder and paranoid personality disorder. Depression is not uncommon in opiate addicts when they begin treatment, ${ }^{27,28}$ and the high rate of antisocial personality disorder among the voluntary subjects in this study was similar to many reported 
studies. ${ }^{4,6,11}$ However, the low rate of mood disorders and antisocial personality disorder among the incarcerated subjects of this study suggest problems of drug control policy in Taiwan. Because drug addiction is viewed as crime, many heroin addicts with no symptoms of depression or personality disorder are incarcerated. This may be responsible for the dilution in the rate of mood disorders and personality disorders in incarcerated subjects compared to hospital subjects.

The high prevalence rate of mood disorders among hospital heroin addicts in this study suggests that depressed heroin addicts are more motivated to receive treatment. In other words, depressed heroin addicts are more likely to be identified and receive treatment. It has been reported that the most striking characteristic of depressive symptoms and diagnosis in opiate addicts was the high degree of fluctuation. ${ }^{29}$ Moreover, when life-time vulnerability to depression is assessed, the opiate addicts have been shown to be at high risk for major depressive episodes and some dysphoric disorders. ${ }^{30}$ Psychiatric services should be open and easily accessible to those who voluntarily seek help because of opioid-related psychiatric disorders, especially mood disorders.

We found a significant difference between subjects with personality disorders (most of them were antisocial) and those without personality disorders in the distribution of social class, comorbidity with axis I disorders and age of first heroin use, but no difference in additional criminal record other than heroin addiction (see Table 3). This supports our observation that currently, in Taiwan, there is a group of people of relatively high socio-economic status who are particularly vulnerable to various psychopathological conditions (such as mood disorders), are antisocial and who become addicted to heroin in young adulthood, perhaps because of noveltyseeking behaviours. The pluralization of social change together with increased economic prosperity may play an important role in the initiations of heroin use. This provides in explanation for the heterogeneity of heroin addicts and the complicated interactions of heroin addiction and coexisting psychopathological as well as social conditions. ${ }^{5,11}$

Historically, like many countries in the Southeast Asia, Taiwan was severely affected by opiate abuse from the end of the nineteenth century until the end of World War II. However, it seems that strict law enforcement has not been able to prevent the recurrence of the current epidemic (since 1989). During the past few years, many efforts have been made in the fight against drug abuse. On the other hand, the pursuit of treatment modalities for heroin addiction is still in its early stages in Taiwan. Historical factors appear responsible for the reluctance of policy makers to decriminalize drug abuse, in particular narcotics, even if the individuals involved have no criminal record other than heroin addiction. There has also been resistance to implementation of a methadone maintenance treatment programme in Taiwan, even though evidence suggests such programme is effective at helping heroin addicts to stop or reduce heroin use. ${ }^{31}$ Undoubtedly, there is still a long way to go to deal adequately with the problems of heroin addiction in Taiwan. The results of this study suggest, to some extent, that heroin addicts who have coexisting psychiatric disorders should receive relevant treatment before their sentence, during their stay in prison. Those addicts with personality disorders, especially the antisocial type, should be considered for a specialized therapeutic community programme instead of incarceration.

\section{Acknowledgements}

This research has been supported by the National Department of Health, Taiwan (DOH 84-TD-079 and DOH 85-TD-108). We wish to express our gratitude to the staff of the Yunlin and Penghu prisons for their assistance throughout the course of this study.

\section{References}

1. Rounsaville, B. J., Weissman, M. M., Kleber, H. \& WILBER, C. (1982) Heterogeneity of psychiatric diagnosis in treated opiate addicts, Archives of General Psychiatry, 39, 161-166.

2. Dorus, W. \& Senay E. C. (1980) Depression, demographic dimensions, and drug abuse, American fournal of Psychiatry, 137, 699-704.

3. Ross, H. E., Glaser, F. B. \& Germanson, T. (1988) The prevalence of psychiatric disorders in patients with alcohol and other drug problems, Archives of General Psychiatry, 45, 1023-1031.

4. Kosten, T. R., Rounsaville B. J. \& Kleber, H. D. (1982) DSM-III personality disorders in opiate addicts, Comprehensive Psychiatry, 23, 572581.

5. Nace, E. P., Davis, C. W. \& Gaspari, J. P. 
(1991) Axis II co-morbidity in substance abusers, American fournal of Psychiatry, 148, 118-120.

6. Dejong C. A. J., VAN DEN BRINK, W., Harteveld, F. M. \& VAN der Wielen, E. G. M. (1993) Personality disorders in alcoholics and drug addicts, Comprehensive Psychiatry, 34, 8794.

7. Darke, S., Wodak, A., Hall, W., Heather, N. \& WARD, J. (1992) Prevalence and predictors of psychopathology among opioid users, British fournal of Addiction, 87, 771-776.

8. Swift, W., Williams, G., Neill, O. \& Grenyer, B. (1990) The prevalence of minor psychopathology in opioid users seeking treatment, British fournal of Addiction, 85, 629-634.

9. Kosten, T. R., Rounsaville, B. J. \& Kieber, H. D. (1986) A 2.5-year follow-up of depression, life crises and treatment effects on abstinence among opioid addicts, Archives of General Psychiatry, 43, 733-738.

10. Rounsaville, B. J., Kosten, T. \& Kleber, H. (1985) Success and failure at outpatient opioid detoxification. Evaluating the process of clonidine- and methadone-assisted withdrawal, Fournal of Nervous and Mental Disease, 173, 103110.

11. Khantzian, E. J. \& Treece, C. (1985) DSM-III psychiatric diagnosis on narcotic addicts, Archives of General Psychiatry, 42, 1067-1071.

13. Hwu, H. G. \& YANG, S. Y. (1988) Psychiatrist diagnosis assessment: establishment and interrater reliability, Chinese Psychiatry, 2, 267-278.

14. Pfohl, B., Blum, N., Zimmerman, M. \& STANGL, D. (1989) The Structured Interview for DSM-III-R Personality (University of Iowa, Department of Psychiatry).

15. Tsai, S. Y., Chen, C. C. \& Yeh, E. K. (1997) Alcohol problems and long-term psychosocial outcome in Chinese bipolar disorder. Fournal of Affective Disorders, 46, 143-150.

16. Stangl, D., Pfohl, B., Zimmerman, M., BowERS, W. \& CORENTHAL, C. (1985) A structured interview for DSM-III personality disorders: a preliminary report, Archives of General Psychiatry, 42, 591-596.

17. Pfhol, B., Stangl, D. \& Zimmerman, $M$. (1984) The implications of DSM-III personality disorders for patients with major depression, Fournal of Affective Disorders, 7, 309-318.

18. Zimmerman, M., Coryell, W., Pfohl, B., Corenthal, C. \& Stangl, D. (1986) ECT response in depressed patients with and without a DSM-III personality disorder, American fournal of Psychiatry, 143, 1030-1032.
19. Hwu, H. G., Yeh, E. K. \& Chang, L. Y. (1989) Prevalences of psychiatric disorders in Taiwan defined by the Chinese Diagnostic Interview Schedule, Acta Psychiatrica Scandinavica, 79, 136-147.

20. Lehman, W. E. K., Barrette, M. E. \& Simpsor, D. D. (1990) Alcohol use by heroin addicts: 12 years after drug abuse treatment, fournal of Studies on Alcohol, 51, 233-244.

21. Belenko, S. (1979) Alcohol abuse by heroin addicts: review of research findings and issues, International fournal of Addiction, 14, 965-975.

22. Rounsaville, B. J., Weisman, M. M. \& Kleber, H. D. (1982) The significance of alcoholism in treated opiate addicts, fournal of Nervous and Mental Disease, 170, 479-488.

23. Chen, C. C., Hwu, H. G., YeH, E. K., Moriмото, K. \& Oтsuki, S. (1991) Aldehyde dehydrogenase deficiency, flush patterns and prevalence of alcoholism: an interethnic comparison, Acta Medica Okayama, 45, 409-417.

24. Miller, N. S., Klamen, D., Hoffmann, N. G. \& Flaherty, J. A. (1996) Prevalence of depression and alcohol and other drug deoendence in addictions treatment. populations, fournal of Psychoactive Drugs, 28, 111-123.

25. USDHHS (1993) Alcohol and Health, Eighth Special Report to the US Congress, pp. 37-59, NIH Publication, No. 94-3699.

26. BERKSON, J. (1949) Limitations of the application of four-fold tables on hospital data, Biological Bulletin, 2, 47-53.

27. Rounsaville, B. J., Rosenberger, P., Wilber, C. et al. (1980) A comparison of the SADS/RDC and the DSM-III: diagnosing drug abusers, fournal of Nervous and Mental Disease, 168, 90-97.

28. Rounsaville, B. J., Weissman, M. M. \& RosenBERGER, P. H. et al. (1979) Detecting depressive disorders in drug abusers: a comparison of screening instruments, fournal of Affective Disorders, 1, 255-267.

29. Rounsaville, B. J., Weissman, M. M., CritsChristoph, K., Wilber, C. \& KLeber, H. (1982) Diagnosis and symptoms of depression in opiate addicts, Archives of General Psychiatry, 39, 151156.

30. Rounsaville, B. J., Kosten, T. \& Kleber, H. (1986) Long-term changes in current psychiatric diagnosis of treated opiate addicts, Comprehensive Psychiatry, 27, 480-498.

31. American Psychiatric Association (APA) (1994) Position statement on methadone maintenance treatment, American fournal of Psychiatry, 151, 792-794. 